\title{
Evidence from $a b$ initio and transport modeling for diffusion-driven zirconium isotopic fractionation in igneous rocks
}

Xi Chen ${ }^{1 *}$, Wenzhong Wang ${ }^{2,3}$, Zhe Zhang ${ }^{1}$, Nicole Xike Nie ${ }^{4}$, Nicolas Dauphas $^{1}$

${ }^{1}$ Origins Laboratory, Department of the Geophysical Sciences and Enrico Fermi Institute, The University of Chicago, Chicago, IL 60637, USA

${ }^{2}$ School of Earth and Space Sciences, University of Science and Technology of China, Hefei, 230026, China

${ }^{3}$ Department of Earth Sciences, University College London, London, WC1E 6BT, UK ${ }^{4}$ Carnegie Institution for Science, Washington, DC 20005, USA

\section{Supporting Information}

(A) Derivation of diffusion-driven kinetic isotopic effects produced by the accumulation of an incompatible element in a diffusive boundary layer.

(B) Supplementary Figures.

(C) Supplementary Tables.

(D) Titles and captions for every movie.

(E) Movies. 
(A) Derivation of diffusion-driven kinetic isotopic effects produced by the accumulation of an incompatible element in a diffusive boundary layer.

\section{(i) General equations for the liquid concentration during transient}

Smith et al. ${ }^{1}$ provide analytical equations of concentration profiles for planar crystal growth at constant rate. The general equation for the concentration in the liquid at some distance $x_{l}$ from the advancing interface relative to the concentration in the far field (or the initial liquid concentration) is,

$\frac{C_{l}\left(x_{l}\right)}{C_{0}}=1+\frac{1-K}{2 K} \exp \left(-\frac{\dot{R}}{D} x_{l}\right) \operatorname{erfc}\left(\frac{x_{l}-\dot{R} t}{2 \sqrt{D t}}\right)-\frac{1}{2} \operatorname{erfc}\left(\frac{x_{l}+\dot{R} t}{2 \sqrt{D t}}\right)+\left(1-\frac{1}{2 K}\right) \exp [-(1-$ K) $\left.\frac{\dot{R}}{D}\left(x_{l}+K \dot{R} t\right)\right] \operatorname{erfc}\left[\frac{x_{l}+(2 K-1) \dot{R} t}{2 \sqrt{D t}}\right]$,

where $x_{l}$ is the distance measured from the interface, $C_{0}$ is the concentration in the liquid at infinity, $K$ is the solid/liquid partition coefficient, $\dot{R}$ is the growth rate (constant), and $D$ is the diffusivity of the trace element in the liquid. If we express the concentration in terms of dimensionless distance $u$,

$u=\frac{\dot{R}}{D} x_{l}$,

and dimensionless time $w$,

$w=\frac{\dot{R}^{2} t}{D}$,

then the concentration in the liquid can be rewritten as,

$$
\begin{aligned}
& \frac{C_{l}\left(x_{l}\right)}{C_{0}}=1+\frac{1-K}{2 K} \exp (-u) \operatorname{erfc}\left(\frac{u-w}{2 \sqrt{w}}\right)-\frac{1}{2} \operatorname{erfc}\left(\frac{u+w}{2 \sqrt{w}}\right)+\left(1-\frac{1}{2 K}\right) \exp [-(1-\mathrm{K})(u+ \\
& K w)] \operatorname{erfc}\left[\frac{u+(2 K-1) w}{2 \sqrt{w}}\right] . \quad \text { (A4) }
\end{aligned}
$$




\section{(ii) General equations for the liquid isotopic composition during transient}

Following Sio et al. ${ }^{2}$, we can use the expressions for the concentration profile to calculate the isotopic composition profile. We write the concentration as a function of diffusivity $D$ and partition coefficient $K$ as,

$C_{l}=f(D, K) \times C_{0}$

If we consider two isotopes 2 and 1, we can write,

$\frac{C_{l, 1}}{C_{0,1}}=f\left(D_{1}, K_{1}\right)$,

$\frac{C_{l, 2}}{C_{0,2}} \simeq f\left(D_{1}, K_{1}\right)+\frac{\partial f}{\partial D} \times\left(D_{2}-D_{1}\right)+\frac{\partial f}{\partial K} \times\left(K_{2}-K_{1}\right)$.

The isotopic ratio is therefore,

$\frac{C_{l, 2} / C_{l, 1}}{C_{0,2} / C_{0,1}} \simeq 1+\frac{D}{f} \frac{\partial f}{\partial D} \times\left(\frac{D_{2}}{D_{1}}-1\right)+\frac{K}{f} \frac{\partial f}{\partial K} \times\left(\frac{K_{2}}{K_{1}}-1\right)$.

In $\delta$ notation, this can take the form,

$\delta_{l} \simeq D \frac{\partial \ln f}{\partial D} \times\left(\frac{D_{2}}{D_{1}}-1\right) \times 1000+K \frac{\partial \ln f}{\partial K} \times\left(\frac{K_{2}}{K_{1}}-1\right) \times 1000$.

We introduce the following notations,

$\Delta_{D} \simeq\left(\frac{D_{2}}{D_{1}}-1\right) \times 1000$,

$\Delta_{K} \simeq\left(\frac{K_{2}}{K_{1}}-1\right) \times 1000$,

where $\Delta_{K}$ is the equilibrium isotopic fractionation between solid and liquid. The isotopic composition in the liquid then takes the form,

$\delta_{l} \simeq D \frac{\partial \ln f}{\partial D} \times \Delta_{D}+K \frac{\partial \ln f}{\partial K} \times \Delta_{K}$.

From the concentration profile (eq. A4), 
$D \frac{\partial \ln f}{\partial D}=$

$\frac{e^{-K w-\frac{(u+w)^{2}}{4 w}}(-1+K)\left\{2 e^{u+K w} K \sqrt{w}+e^{\frac{(u+w)^{2}}{4 w}} \sqrt{\pi}\left[-e^{K w} u \times \operatorname{erfc}\left(\frac{u-w}{2 \sqrt{w}}\right)-e^{K(u+K w)}(-1+2 K)(u+K w) \operatorname{erfc}\left(\frac{u+(2 K-1) w}{2 \sqrt{w}}\right)\right]\right\}}{\left\{\sqrt{\pi}\left[e^{u} K+e^{u} K \times \operatorname{erfc}\left(\frac{u+w}{2 \sqrt{w}}\right)-(-1+K) \operatorname{erfc}\left(\frac{u-w}{2 \sqrt{w}}\right)+e^{K(u+(-1+K) w)}(-1+2 K) \operatorname{erfc}\left(\frac{u+(2 K-1) w}{2 \sqrt{w}}\right)\right]\right\}}$

, (A13)

$K \frac{\partial \ln f}{\partial K}=$

$\frac{\left.e^{-\frac{(u+w)^{2}}{4 w}}\left\{2 e^{u} K(-1+2 K) w+\sqrt{\pi} \sqrt{w}\left[e^{\frac{(u+w)^{2}}{4 w}} \operatorname{erfc}\left(\frac{u-w}{2 \sqrt{w}}\right)-e^{\frac{1}{4}\left((2+4 K) u+\frac{u^{2}}{w}+(1-2 K)^{2} w\right.}\right)(1+K(-1+2 K)(u+(-1+2 K) w)) \operatorname{erfc}\left(\frac{u+(2 K-1) w}{2 \sqrt{w}}\right)\right]\right\}}{\left\{\sqrt{\pi} \sqrt{w}\left[(-1+K) \operatorname{erfc}\left(\frac{u-w}{2 \sqrt{w}}\right)+e^{u} K\left(-2+\operatorname{erfc}\left(\frac{u+w}{2 \sqrt{w}}\right)\right)-e^{K(u+(-1+K) w)}(-1+2 K) \operatorname{erfc}\left(\frac{u+(2 K-1) w}{2 \sqrt{w}}\right)\right]\right\}}$

(A14)

Combining equations (A12- A14) gives the isotopic composition in the liquid as a

function of time and distance from the interface.

(iii) Liquid concentration and isotopic composition at steady-state

Smith et al. ${ }^{1}$ also provide the analytical equation of the concentration profile in the liquid at steady-state,

$\frac{C_{l}\left(x_{l}\right)}{C_{0}}=1+\frac{1-K}{K} \exp \left(-\frac{\dot{R}}{D} x_{l}\right)=1+\frac{1-K}{K} \exp (-u)$.

In the same manner as outlined above, we calculate that the isotopic composition at steady-state in $\delta$ notation is,

$\delta_{l} \simeq \frac{(1-K) u}{1+K\left(e^{u}-1\right)} \Delta_{D}+\frac{1}{K-1-K e^{u}} \Delta_{K}$.

(iv) Maximum isotopic fractionation in the liquid at steady-state

At steady-state, we can also calculate the maximum isotopic fractionation in the liquid in the diffusive boundary layer. In equation (A16), we set $\Delta_{K}=0$, so we have, 
$\delta_{l} \simeq \frac{(1-K) u}{1+K\left(e^{u}-1\right)} \Delta_{D}$

The location of the maximum isotopic composition is calculated by solving for $u$ in the following equation,

$\frac{\partial \delta_{l}}{\partial u}=\frac{\Delta_{D}(K-1)\left(K-1+e^{u} K(u-1)\right.}{\left(1+\left(e^{u}-1\right) K\right)^{2}}=0$,

and then injecting it in eq. A17, which yields,

$\delta_{l}=\Delta_{D} \times$ Product $\log \left[\frac{1-K}{e K}\right]$

where Product $\log [z]$ is the principal solution for the transcendental equation $z=$ $w e^{w}$

\section{(v) Concentration and isotopic composition in the solid}

For the growing solid, the distance between the solid-liquid interface and the origin of the solid (position of the interface at time zero) is

$x_{s}=\dot{R} t$

The concentration in the solid is equal to $K$ times the liquid concentration at $x_{l}=0$ or $u=0$, thus in the transient, the concentration in the growing solid is,

$C_{S}\left(x_{s}\right)=C_{l\left(x_{l}=0\right)} \times K$

From equation (A4), we have,

$\frac{C_{S}\left(x_{S}\right)}{C_{0}}=K-\frac{1}{2} \operatorname{erfc}\left(\frac{\sqrt{w}}{2}\right)+\left(\mathrm{K}-\frac{1}{2}\right) \exp [-\mathrm{K}(1-\mathrm{K}) w] \operatorname{erfc}\left[\frac{(2 K-1) \sqrt{w}}{2}\right]$,

and the isotopic composition in the growing solid is,

$\delta_{s}=\delta_{l(u=0)}+\Delta_{K}$

$\delta_{S}=D \frac{\partial \ln f}{\partial D}(u=0) \times \Delta_{D}+\left[1+K \frac{\partial \ln f}{\partial K}(u=0)\right] \times \Delta_{K}$.

From equations (A13) and (A14), we have, 
$D \frac{\partial \operatorname{lnf}}{\partial D}(u=0)=\frac{e^{-\frac{1}{4}(1+4 K) w}(-1+K)\left[2 e^{K w} K \sqrt{w}-e^{\left(\frac{1}{4}+K^{2}\right) w} K(-1+2 K) \sqrt{\pi} w \times \operatorname{erfc}\left(\frac{(2 K-1) \sqrt{w}}{2}\right)\right]}{\sqrt{\pi}\left[K+K \times \operatorname{erfc}\left(\frac{\sqrt{w}}{2}\right)-(-1+K) \operatorname{erfc}\left(-\frac{\sqrt{w}}{2}\right)+e^{(-1+K) K w}(-1+2 K) \operatorname{erfc}\left(\frac{(2 K-1) \sqrt{w}}{2}\right)\right]}$

$1+K \frac{\partial \ln f}{\partial K}(u=0)=$

$\frac{1+2 e^{-\frac{w}{4}} K(-1+2 K) w+\sqrt{\pi} \sqrt{w}\left[1+\operatorname{erfc}\left(\frac{\sqrt{w}}{2}\right)-e^{(-1+K) K w}\left(1+(1-2 K)^{2} K w\right) \operatorname{erfc}\left(\frac{(2 K-1) \sqrt{w}}{2}\right)\right]}{\sqrt{\pi} \sqrt{w}\left[(-1+K) \operatorname{erfc}\left(-\frac{\sqrt{w}}{2}\right)+K\left(-2+\operatorname{erfc}\left(\frac{\sqrt{w}}{2}\right)\right)-e^{(-1+K) K w}(-1+2 K) \operatorname{erfc}\left(\frac{(2 K-1) \sqrt{w}}{2}\right)\right]}$,

and at steady-state for the solid, $C_{s}\left(x_{s}\right)=C_{0}, \delta_{s}=0$.

\section{(B) Supplementary Figures.}

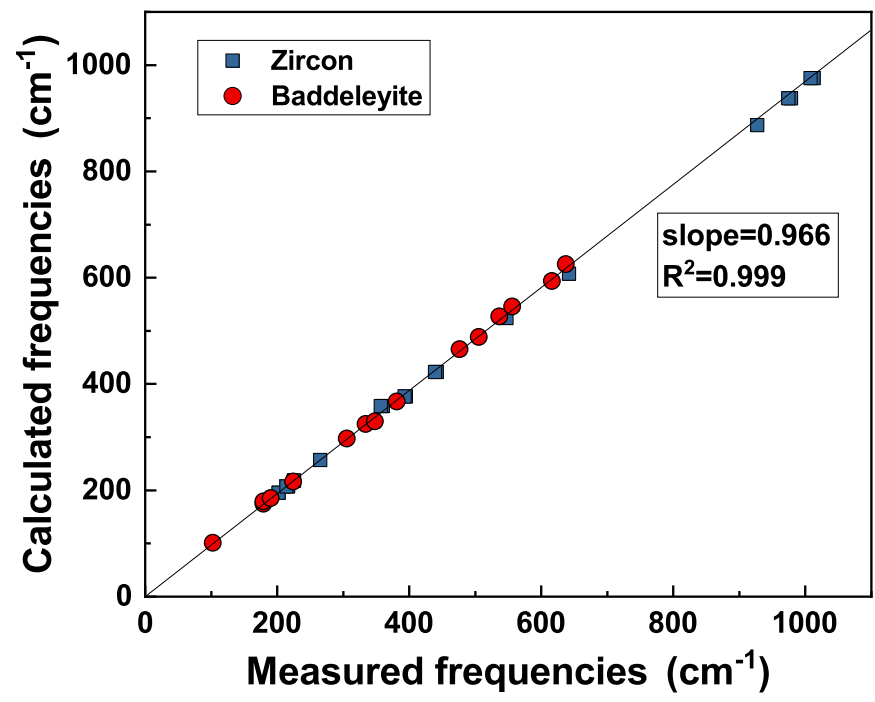

Figure S1. Comparison of the calculated vibrational frequencies with experimental data (Raman spectra) with the same vibrational modes. Experimental data sources: zircon $^{3,4}$; baddeleyite ${ }^{5}$. 

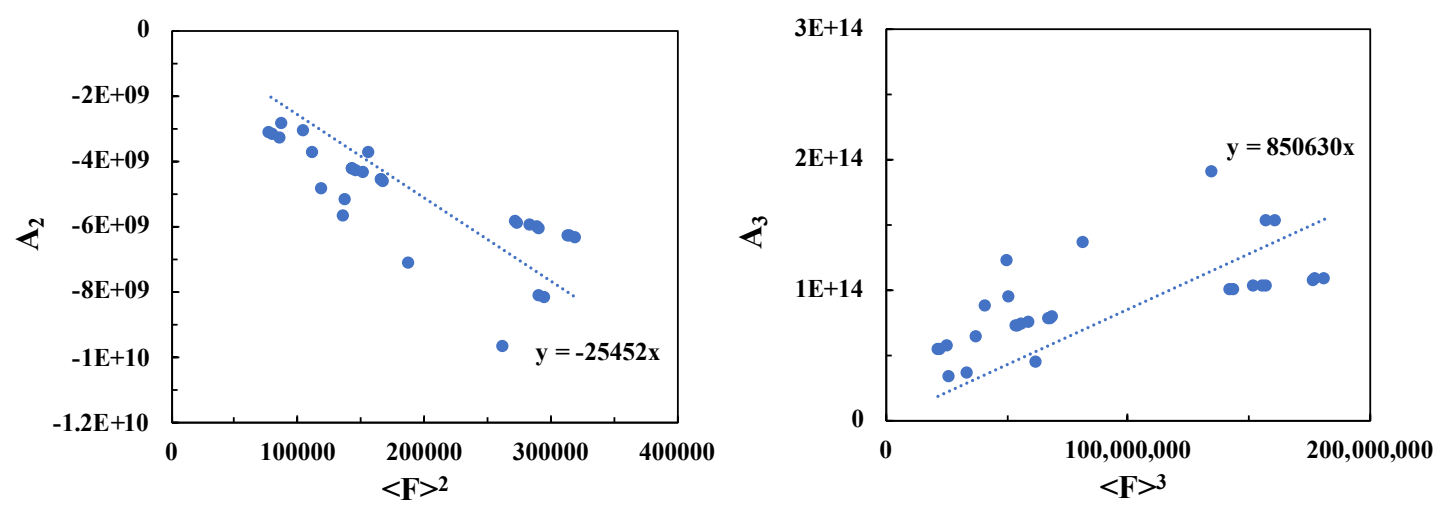

Figure S2. Polynomial expansion coefficient (left) $A_{2} v_{S}\langle F\rangle^{2}$ and (right) $A_{3} v s\langle F\rangle^{3}$ for $1000 \ln \beta\left({ }^{94} \mathrm{Zr} /{ }^{90} \mathrm{Zr}\right)$. The regressions give the estimated values of $\mathrm{B}_{2}$ and $\mathrm{B}_{3}$ in the one-parameter approximate formula (see eq. 9 and 10).
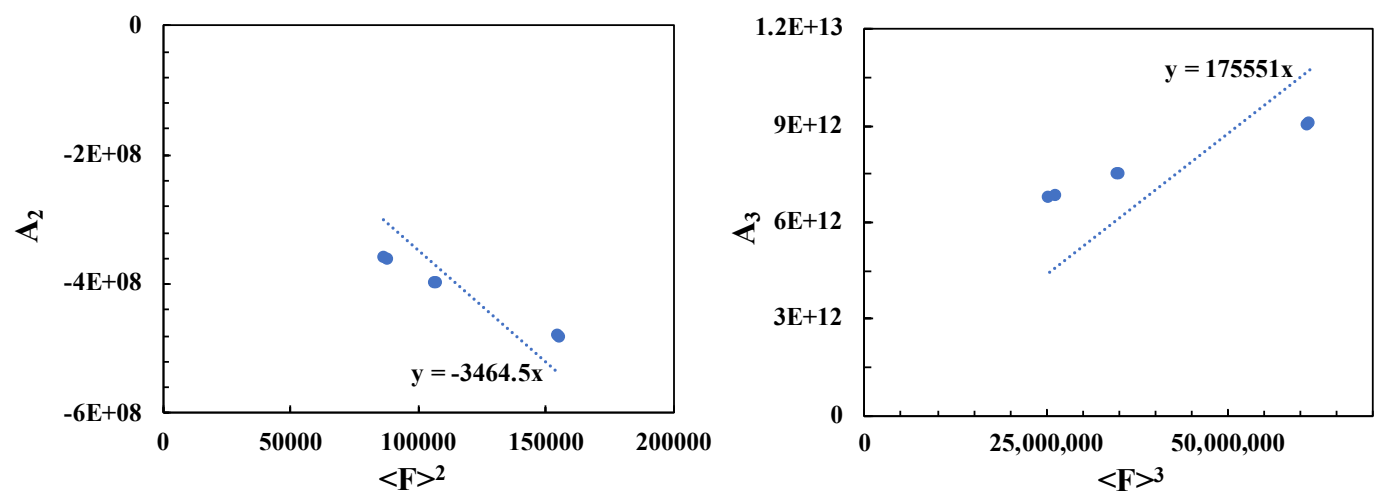

Figure S3. Polynomial expansion coefficient (left) $A_{2} v s\langle F\rangle^{2}$ and (right) $A_{3} v s\langle F\rangle^{3}$ for $1000 \ln \beta\left({ }^{179} \mathrm{Hf} /{ }^{177} \mathrm{Hf}\right)$. The regressions give the estimated values of $\mathrm{B}_{2}$ and $\mathrm{B}_{3}$ in the one-parameter approximate formula (see eq. 9 and 12). 

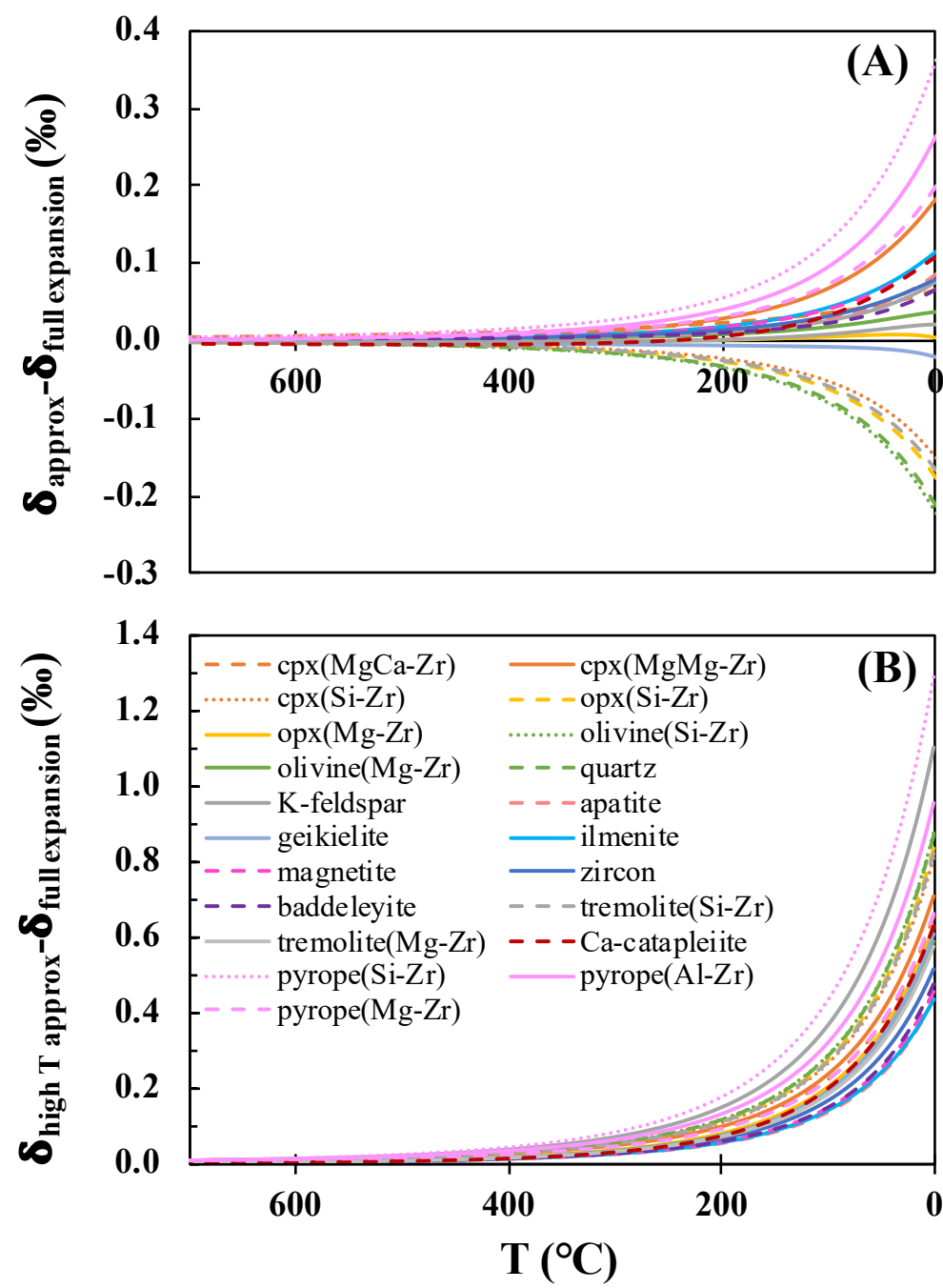

Figure S4. Differences of $\mathrm{Zr} 1000 \ln \beta$ between (A) the 1-parameter 3-term expansion (eq. 9) and the full polynomial expansion equation (eq. 4), and (B) the 1-parameter 1term high-temperature approximation (eq. 9 truncated to the first term) and the full polynomial expansion equation (eq. 4). 

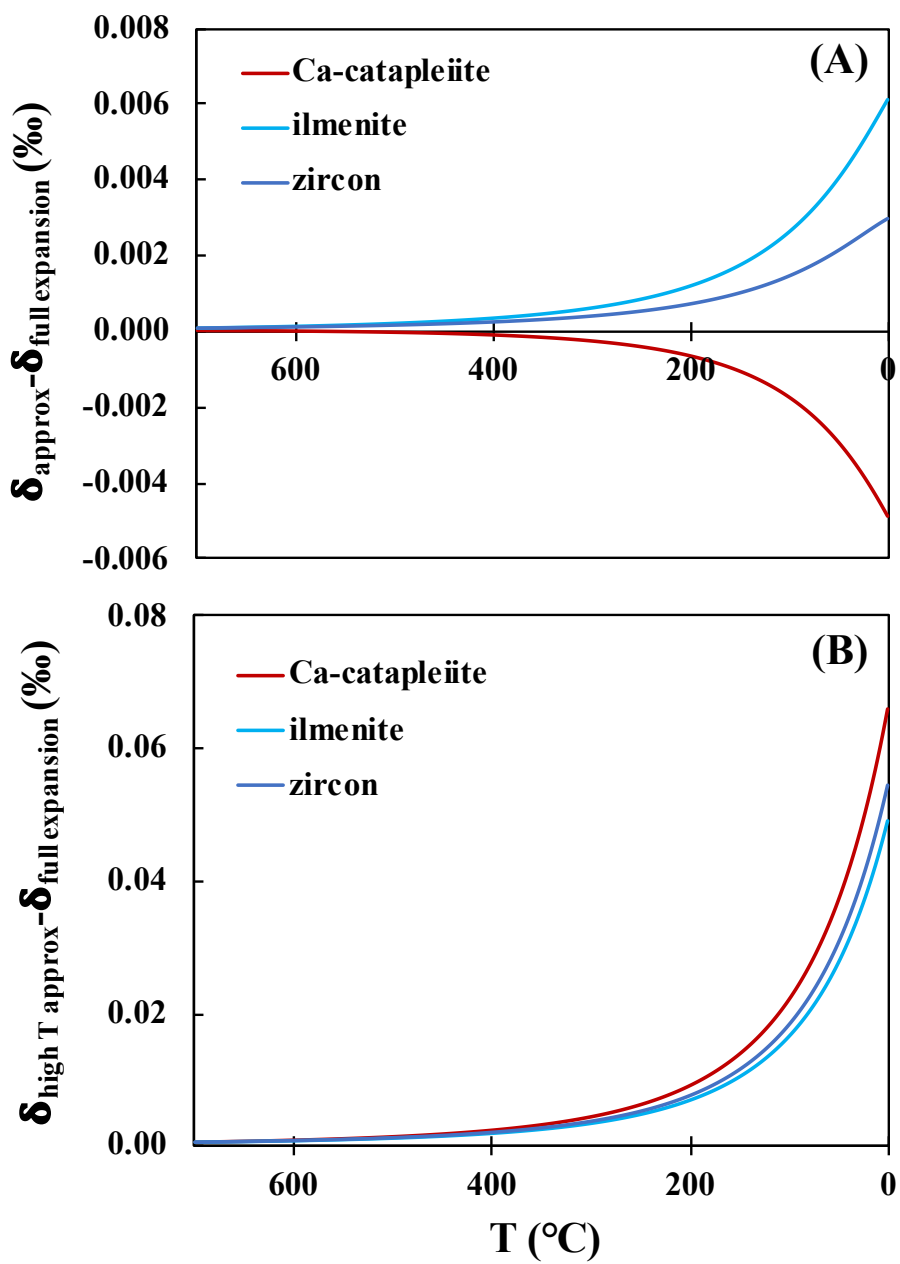

Figure S5. Same as Figure S4 but for Hf rather than Zr. 

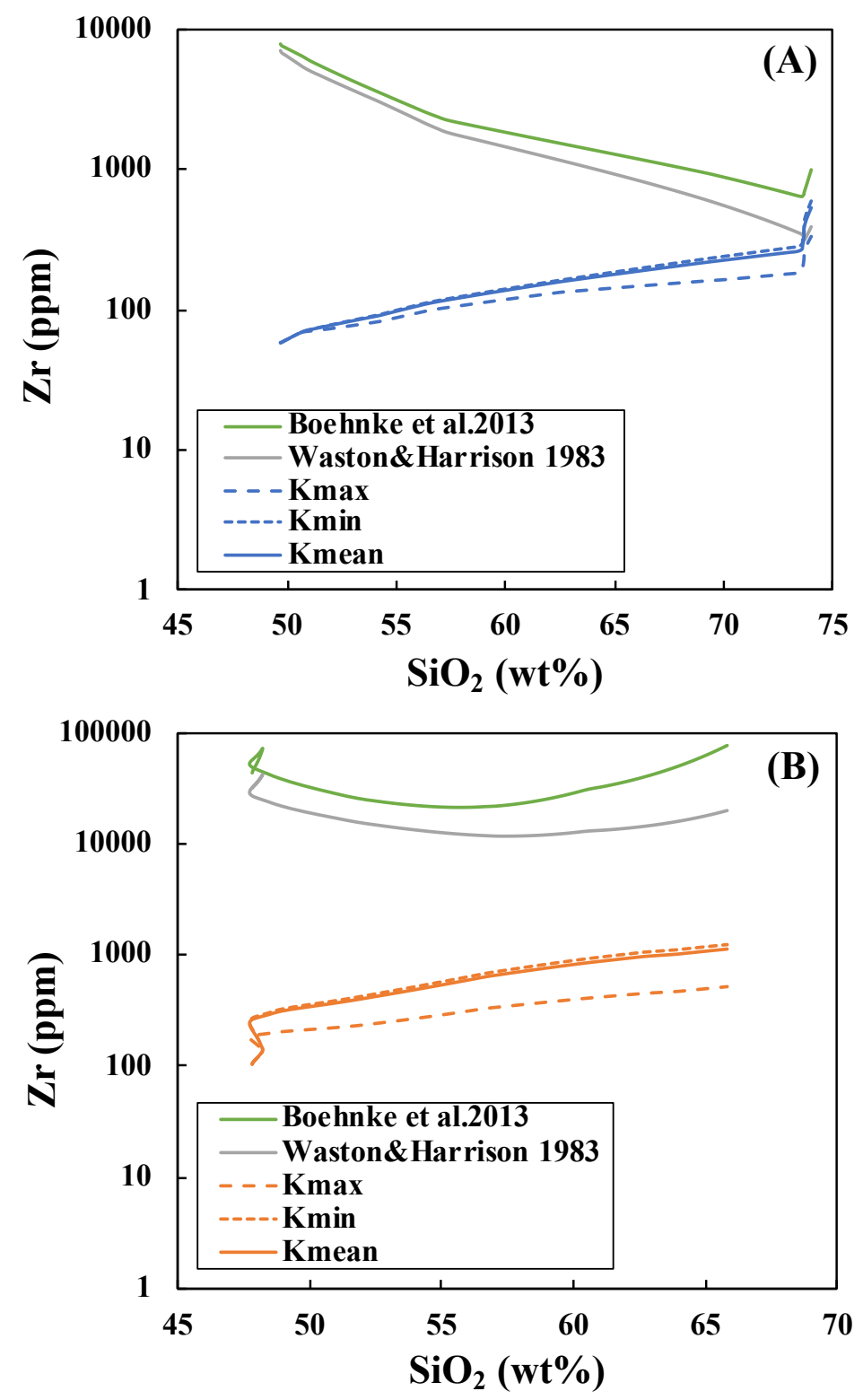

Figure S6. Evolution of Zr concentration remaining in the melt (blue and orange curves) and zircon saturation during fractional crystallization of a (A) calc-alkaline and (B) tholeiitic magmas. Calculations are done with different bulk partition coefficients $(\mathrm{K})$ using the modeled mineral assemblage results of the Rhyolite-MELTS program (i.e., Figure 9). The zircon saturation curves (green and gray lines) were calculated using Waston and Harrison ${ }^{6}$ and Boehnke et al. $^{7}$ and taking the melt major-element compositions and temperature from the Rhyolite-MELTS program as input. The initial compositions used in Rhyolite-MELTS modeling are (A) calc-alkaline ${ }^{8}$ (in wt\%) $\mathrm{SiO}_{2}$ : 49.7; $\mathrm{TiO}_{2}: 0.99 ; \mathrm{Al}_{2} \mathrm{O}_{3}: 18.39 ; \mathrm{Fe}_{2} \mathrm{O}_{3}: 2.13 ; \mathrm{Cr}_{2} \mathrm{O}_{3}$ : 0; $\mathrm{FeO}: 9.00 ; \mathrm{MnO}: 0.19 ; \mathrm{MgO}$ : 5.46; $\mathrm{CaO}: 8.94 ; \mathrm{Na}_{2} \mathrm{O}: 2.49 ; \mathrm{K}_{2} \mathrm{O}: 0.69 ; \mathrm{P}_{2} \mathrm{O}_{5}: 0.19 ; \mathrm{H}_{2} \mathrm{O}: 1.78 ; \mathrm{P}: 1 \mathrm{kbar} ;$ (B) tholeiitic ${ }^{9}$ (in wt\%) $\mathrm{SiO}_{2}$ : 47.78; $\mathrm{TiO}_{2}: 1.98 ; \mathrm{Al}_{2} \mathrm{O}_{3}: 17.31 ; \mathrm{Fe}_{2} \mathrm{O}_{3}: 1.22 ; \mathrm{Cr}_{2} \mathrm{O}_{3}: 0.04 ; \mathrm{FeO}:$ 7.66; MnO: 0; $\mathrm{MgO}: 8.92 ; \mathrm{CaO}: 12.2 ; \mathrm{Na}_{2} \mathrm{O}: 2.58 ; \mathrm{K}_{2} \mathrm{O}: 0.02 ; \mathrm{P}_{2} \mathrm{O}_{5}: 0.07 ; \mathrm{H}_{2} \mathrm{O}: 0.2 ; \mathrm{P}: 0.6$ kbar. 

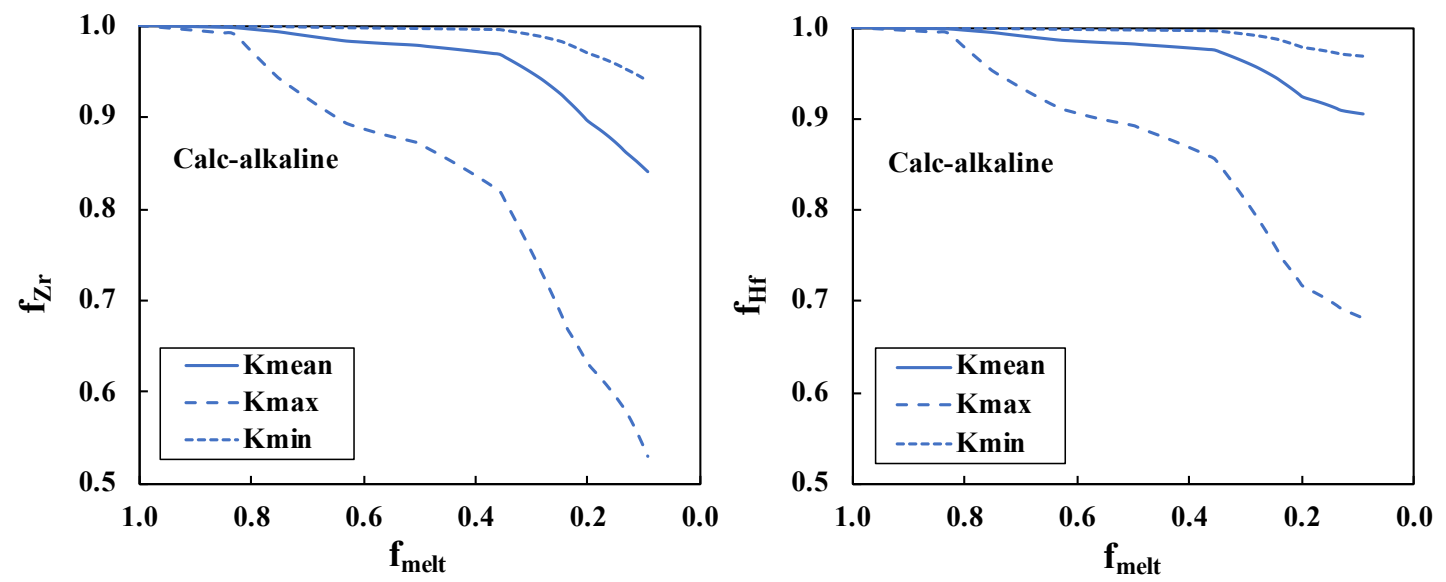

Figure S7. Fractions of $\mathrm{Zr}$ (left) and $\mathrm{Hf}$ (right) remaining in the melt as a function of the mass fraction of the residual melt for calc-alkaline magma during fractional crystallization before zircon starts to crystallize. These curves were calculated with the Rhyolite-MELTS program (see Section 4.2. for details).
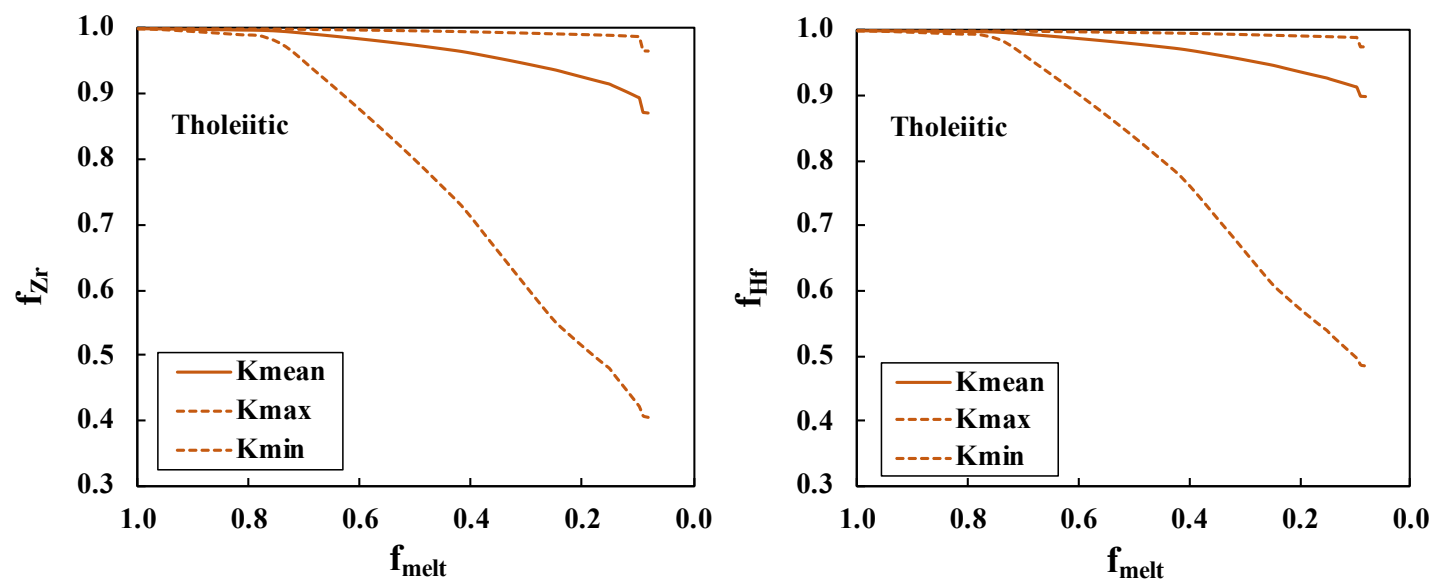

Figure S8. Same as Figure S7 but for a tholeiitic magma. 


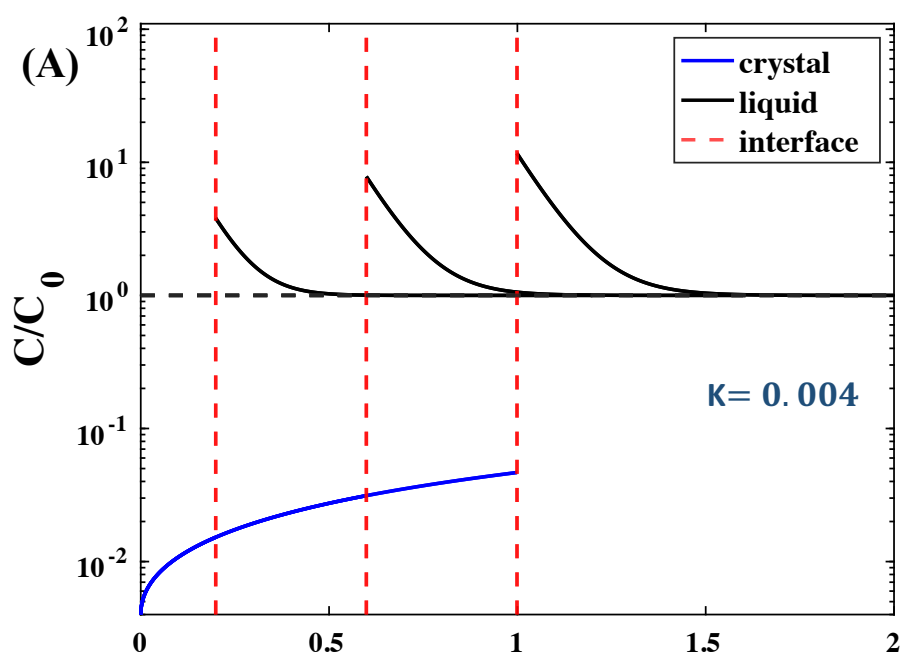

Distance to initial liquid/crystal interface (cm)

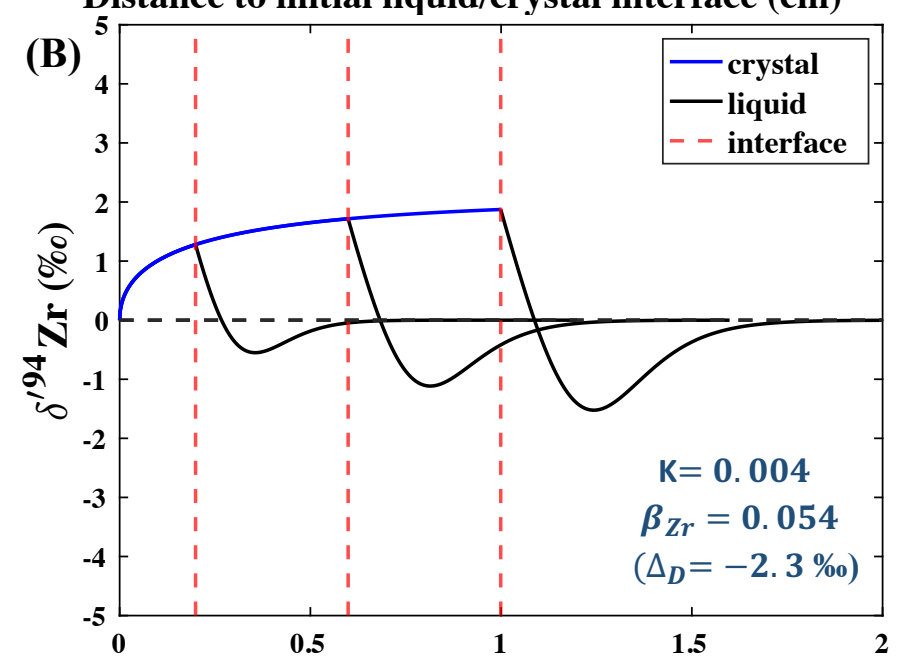

Distance to initial liquid/crystal interface (cm)

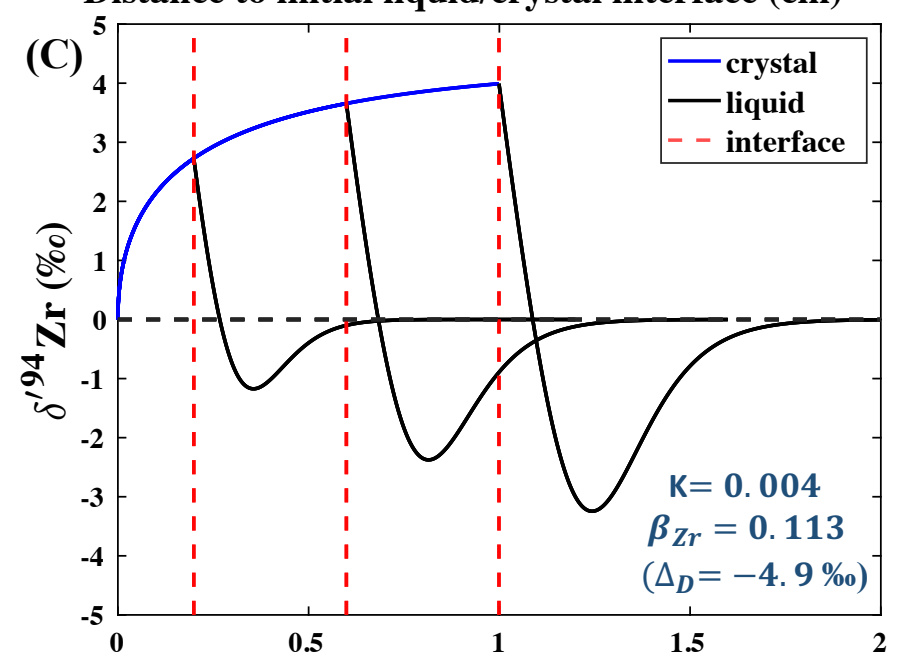

Distance to initial liquid/crystal interface $(\mathrm{cm})$

Figure S9. Same as Figure 17 except that we use the partition coefficient of plagioclase $K=0.004$ (the geometric mean of the values compiled in GERM database). 


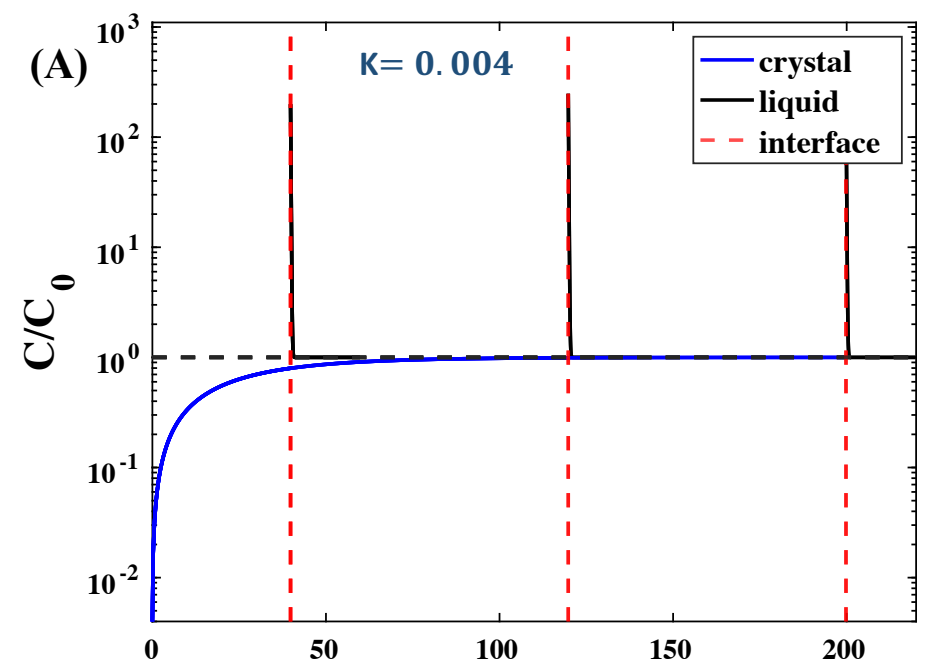

Distance to initial liquid/crystal interface $(\mathbf{c m})$

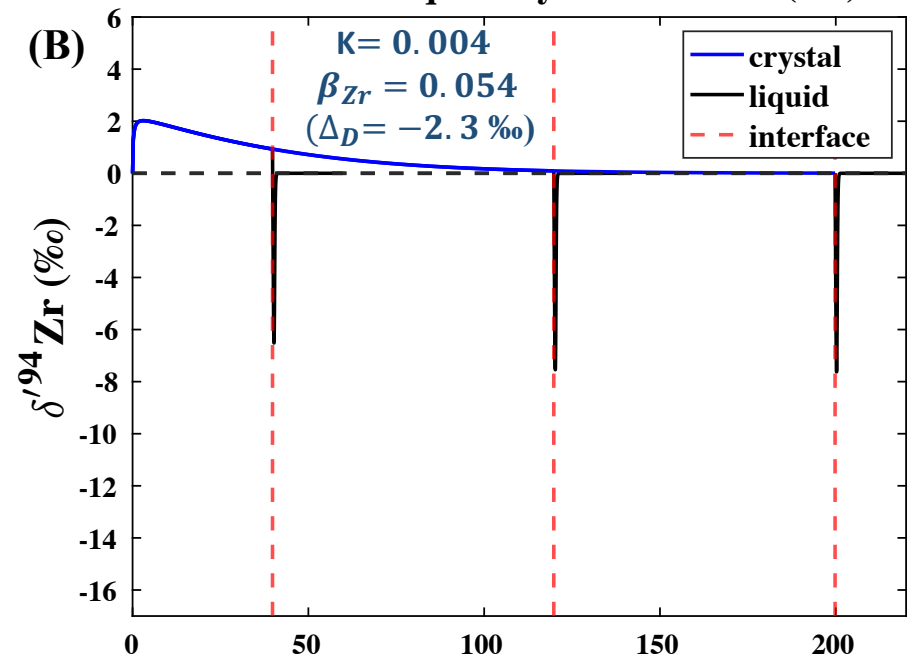

Distance to initial liquid/crystal interface $(\mathbf{c m})$

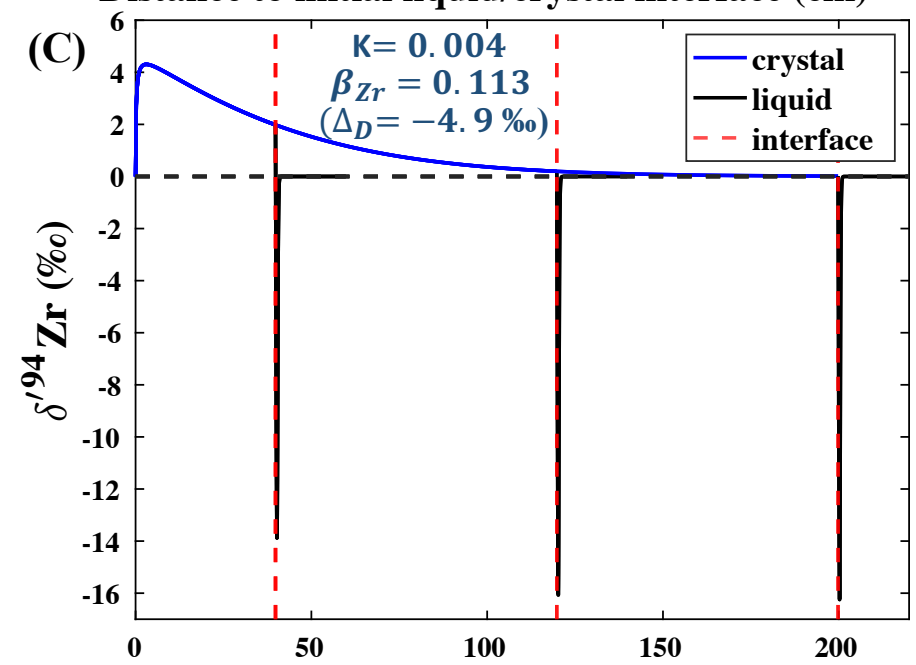

Distance to initial liquid/crystal interface $(\mathbf{c m})$

Figure S10. Same as Figure 18 except that we use the partition coefficient of plagioclase $K=0.004$ (the geometric mean of the values compiled in GERM database), and the three snapshots are taken at 126, 380, and $634 \mathrm{kyr}$. 
(C) Supplementary Tables.

Table S1. The k-point mesh used to calculate Brillouin zone summations over electronic states.

\begin{tabular}{|c|c|c|}
\hline clinopyroxene & Chemical composition & k-point mesh \\
\hline \multirow{2}{*}{$\mathrm{Si}^{4+} \leftrightarrow \mathrm{Zr}^{4+}$} & $\mathrm{Mg}_{24} \mathrm{Ca}_{24} \mathrm{Si}_{47} \mathrm{ZrO}_{144}$ & $1 \times 1 \times 1$ \\
\hline & $\mathrm{Mg}_{32} \mathrm{Ca}_{32} \mathrm{Si}_{63} \mathrm{ZrO}_{192}$ & $1 \times 1 \times 1$ \\
\hline \multirow{2}{*}{${ }^{\mathrm{VI}} \mathrm{Mg}^{2+}+{ }^{\mathrm{VIII}} \mathrm{Ca}^{2+} \leftrightarrow \mathrm{Zr}^{4+}{ }_{\mathrm{Mg}}^{+}$} & $\mathrm{Mg}_{7} \mathrm{ZrCa}_{7} \mathrm{Si}_{16} \mathrm{O}_{48}$ & $1 \times 1 \times 1$ \\
\hline & $\mathrm{Mg}_{15} \mathrm{ZrCa}_{15} \mathrm{Si}_{32} \mathrm{O}_{96}$ & $1 \times 1 \times 1$ \\
\hline${ }^{\mathrm{VI}} \mathrm{Mg}^{2+}+{ }^{\mathrm{VI}} \mathrm{Mg}^{2+} \leftrightarrow \mathrm{Zr}^{4+} \mathrm{Mg}^{+}$ & $\mathrm{Mg}_{6} \mathrm{ZrCa}_{8} \mathrm{Si}_{16} \mathrm{O}_{48}$ & $1 \times 1 \times 1$ \\
\hline \multicolumn{3}{|l|}{ orthopyroxene } \\
\hline \multirow{2}{*}{$\mathrm{Si}^{4+} \leftrightarrow \mathrm{Zr}^{4+}$} & $\mathrm{Mg}_{32} \mathrm{Si}_{31} \mathrm{ZrO}_{96}$ & $1 \times 1 \times 1$ \\
\hline & $\mathrm{Mg}_{64} \mathrm{Si}_{63} \mathrm{ZrO}_{192}$ & $1 \times 1 \times 1$ \\
\hline \multirow{2}{*}{${ }^{\mathrm{V}} \mathrm{Mg}^{2+}(\mathrm{M} 1)+{ }^{\mathrm{VI}} \mathrm{Mg}^{2+}(\mathrm{M} 2) \leftrightarrow{ }^{\mathrm{VI}} \mathrm{Zr}^{4+}+$} & $\mathrm{Mg}_{30} \mathrm{ZrSi}_{32} \mathrm{O}_{96}$ & $1 \times 1 \times 1$ \\
\hline & $\mathrm{Mg}_{62} \mathrm{ZrSi}_{64} \mathrm{O}_{192}$ & $1 \times 1 \times 1$ \\
\hline \multicolumn{3}{|l|}{ olivine } \\
\hline \multirow{2}{*}{$\mathrm{Si}^{4+} \leftrightarrow \mathrm{Zr}^{4+}$} & $\mathrm{Mg}_{32} \mathrm{Si}_{15} \mathrm{ZrO}_{64}$ & $1 \times 1 \times 1$ \\
\hline & $\mathrm{Mg}_{64} \mathrm{Si}_{31} \mathrm{ZrO}_{128}$ & $1 \times 1 \times 1$ \\
\hline \multirow{2}{*}{${ }^{\mathrm{VI}} \mathrm{Mg}^{2+}(\mathrm{M} 2)+{ }^{\mathrm{VI}} \mathrm{Mg}^{2+}(\mathrm{M} 1) \leftrightarrow{ }^{\mathrm{VI}} \mathrm{Zr}^{4+}+$} & $\mathrm{Mg}_{30} \mathrm{ZrSi}_{16} \mathrm{O}_{64}$ & $1 \times 1 \times 1$ \\
\hline & $\mathrm{Mg}_{62} \mathrm{ZrSi}_{32} \mathrm{O}_{128}$ & $1 \times 1 \times 1$ \\
\hline \multicolumn{3}{|l|}{ quartz } \\
\hline \multirow{2}{*}{$\mathrm{Si}^{4+} \leftrightarrow \mathrm{Zr}^{4+}$} & $\mathrm{Si}_{80} \mathrm{ZrO}_{162}$ & $1 \times 1 \times 1$ \\
\hline & $\mathrm{Si}_{95} \mathrm{ZrO}_{192}$ & $1 \times 1 \times 1$ \\
\hline \multicolumn{3}{|l|}{ K-feldspar } \\
\hline \multirow{2}{*}{${ }^{\mathrm{IV}} \mathrm{Al}^{3+}+{ }^{\mathrm{VIII}} \mathrm{K}^{+} \leftrightarrow \mathrm{Zr}^{4+} \mathrm{Al}^{+}$} & $\mathrm{K}_{7} \mathrm{Al}_{7} \mathrm{Si}_{24} \mathrm{O}_{64}$ & $1 \times 1 \times 1$ \\
\hline & $\mathrm{K}_{15} \mathrm{Al}_{15} \mathrm{ZrSi}_{48} \mathrm{O}_{128}$ & $1 \times 1 \times 1$ \\
\hline \multicolumn{3}{|l|}{ apatite } \\
\hline \multirow{2}{*}{${ }^{\mathrm{IX}} \mathrm{Ca}^{2+}+{ }^{\mathrm{VII}} \mathrm{Ca}^{2+} \leftrightarrow \mathrm{Zr}^{4+}+$} & $\mathrm{Ca}_{38} \mathrm{ZrP}_{24} \mathrm{O}_{96} \mathrm{~F}_{8}$ & $1 \times 1 \times 1$ \\
\hline & $\mathrm{Ca}_{78} \mathrm{ZrP}_{48} \mathrm{O}_{192} \mathrm{~F}_{16}$ & $1 \times 1 \times 1$ \\
\hline
\end{tabular}




\begin{tabular}{|c|c|c|}
\hline \multicolumn{3}{|l|}{ geikielite } \\
\hline \multirow{2}{*}{$\mathrm{Ti}^{4+} \leftrightarrow \mathrm{Zr}^{4+}$} & $\mathrm{Mg}_{24} \mathrm{Ti}_{23} \mathrm{ZrO}_{72}$ & $1 \times 1 \times 1$ \\
\hline & $\mathrm{Mg}_{48} \mathrm{Ti}_{47} \mathrm{ZrO}_{144}$ & $1 \times 1 \times 1$ \\
\hline \multicolumn{3}{|l|}{ ilmenite } \\
\hline \multirow{2}{*}{$\mathrm{Ti}^{4+} \leftrightarrow \mathrm{Zr}^{4+}$} & $\mathrm{Fe}_{24} \mathrm{Ti}_{23} \mathrm{ZrO}_{72}$ & $1 \times 1 \times 1$ \\
\hline & $\mathrm{Fe}_{48} \mathrm{Ti}_{47} \mathrm{ZrO}_{144}$ & $1 \times 1 \times 1$ \\
\hline \multicolumn{3}{|l|}{$\mathrm{MgFe}_{2} \mathrm{O}_{4}$ magnetite } \\
\hline \multirow{2}{*}{${ }^{\mathrm{VI}} \mathrm{Fe}^{3+}+{ }^{\mathrm{IV}} \mathrm{Fe}^{3+} \leftrightarrow{ }^{\mathrm{VI}} \mathrm{Zr}^{4+}+{ }^{\mathrm{IV}} \mathrm{Mg}^{2+}$} & $\mathrm{Mg}_{17} \mathrm{ZrFe}_{30} \mathrm{O}_{64}$ & $1 \times 2 \times 2$ \\
\hline & $\mathrm{Mg}_{33} \mathrm{ZrFe}_{62} \mathrm{O}_{128}$ & $1 \times 1 \times 1$ \\
\hline \multicolumn{3}{|l|}{ tremolite } \\
\hline $\mathrm{Si}^{4+} \leftrightarrow \mathrm{Zr}^{4+}$ & $\mathrm{Mg}_{40} \mathrm{Ca}_{16} \mathrm{Si}_{63} \mathrm{ZrH}_{16} \mathrm{O}_{192}$ & $1 \times 1 \times 1$ \\
\hline \multirow{2}{*}{${ }^{\mathrm{VI}} \mathrm{Mg}^{2+}(\mathrm{M} 2)+{ }^{\mathrm{VI}} \mathrm{Mg}^{2+}(\mathrm{M} 1) \leftrightarrow \mathrm{Zr}^{4+}{ }_{\mathrm{M} 2}+$} & $\mathrm{Mg}_{18} \mathrm{ZrCa}_{8} \mathrm{Si}_{32} \mathrm{H}_{8} \mathrm{O}_{96}$ & $1 \times 1 \times 1$ \\
\hline & $\mathrm{Mg}_{38} \mathrm{ZrCa}_{16} \mathrm{Si}_{64} \mathrm{H}_{16} \mathrm{O}_{192}$ & $1 \times 1 \times 1$ \\
\hline \multicolumn{3}{|l|}{ pyrope } \\
\hline${ }^{\mathrm{IV}} \mathrm{Si}^{4+} \leftrightarrow \mathrm{Zr}^{4+}$ & $\mathrm{Mg}_{24} \mathrm{Al}_{16} \mathrm{Si}_{23} \mathrm{ZrO}_{96}$ & $1 \times 1 \times 1$ \\
\hline${ }^{\mathrm{VI}} \mathrm{Al}^{3+}+{ }^{\mathrm{IV}} \mathrm{Si}^{4+} \leftrightarrow \mathrm{Zr}^{4+}+\mathrm{Al}^{3+}$ & $\mathrm{Mg}_{24} \mathrm{Al}_{16} \mathrm{Si}_{23} \mathrm{ZrO}_{96}$ & $1 \times 1 \times 1$ \\
\hline${ }^{\mathrm{VIII}} \mathrm{Mg}^{2+}+{ }^{\mathrm{VIII}} \mathrm{Mg}^{2+} \leftrightarrow \mathrm{Zr}^{4+}+$ & $\mathrm{Mg}_{22} \mathrm{ZrAl}_{16} \mathrm{Si}_{24} \mathrm{O}_{96}$ & $1 \times 1 \times 1$ \\
\hline zircon & $\mathrm{Zr}_{2} \mathrm{Si}_{2} \mathrm{O}_{8}$ & $8 \times 8 \times 8$ \\
\hline baddeleyite & $\mathrm{Zr}_{4} \mathrm{O}_{8}$ & $6 \times 6 \times 6$ \\
\hline Ca catapleiite & $\mathrm{Ca}_{4} \mathrm{Zr}_{4} \mathrm{Si}_{12} \mathrm{H}_{16} \mathrm{O}_{44}$ & $2 \times 1 \times 1$ \\
\hline
\end{tabular}

represents the vacancy. 
Table S2. Calculated cell parameters and volumes of zircon, baddeleyite, and Ca catapleiite under static conditions.

\begin{tabular}{lllllllll}
\hline Minerals & $\mathrm{a}(\AA)$ & $\mathrm{b}(\AA)$ & $\mathrm{c}(\AA)$ & $\alpha\left(^{\mathrm{o}}\right)$ & $\beta\left(^{\mathrm{o}}\right)$ & $\gamma\left(^{\mathrm{o}}\right)$ & Volume $\left(\AA^{3}\right)$ & \\
\hline \multirow{2}{*}{ zircon } & 6.7056 & 6.7056 & 6.0390 & 90.00 & 90.00 & 90.00 & 271.5441 & This study \\
& 6.6102 & 6.6102 & 5.9860 & 90.00 & 90.00 & 90.00 & 261.5567 & Exp. 1 \\
\hline \multirow{2}{*}{ baddeleyite } & 5.2188 & 5.2797 & 5.4052 & 90.00 & 99.67 & 90.00 & 146.8201 & This study \\
& 5.15050 & 5.21160 & 5.31730 & 90.00 & 99.23 & 90.00 & 140.8808 & Exp. 2 \\
\hline \multirow{2}{*}{ Ca catapleiite } & 7.5060 & 12.8808 & 10.1933 & 89.31 & 89.52 & 89.84 & 985.4147 & This study \\
& 7.378 & 12.779 & 10.096 & 90.00 & 90.00 & 90.00 & 951.89 & Exp. 3 \\
\hline
\end{tabular}

Data sources: Exp. $1^{10}$; Exp. $2^{11} ;$ Exp. $3^{12}$.

(D) Titles and captions for every movie.

(i) DLC model

Movie S1: $\mathrm{Zr}$ concentration profiles in the liquid away from the interface of a growing zircon in a diffusion-limited regime (DLC model) until the zircon grows to $10 \mu \mathrm{m}$ in size. The blue line is the liquid-solid interface and the red dot is the liquid concentration at the interface.

Movie S2: Zr isotopic composition profiles in the liquid away from the interface of a growing zircon in a diffusion-limited regime (DLC model) until the zircon grows to $10 \mu \mathrm{m}$ in size.

(ii) DTC model-Transient profiles during growth of a Zr-poor crystal to $1 \mathrm{~cm}$ in size.

Movie S3: Evolution of the Zr concentrations in a growing Zr-poor crystal (blue line) and in the surrounding melt growth medium (black line) until the crystal reaches a size of $1 \mathrm{~cm}$. 
Movie S4: Evolution of the $\mathrm{Zr}$ isotopic compositions in a growing $\mathrm{Zr}$-poor crystal (blue line) and in the surrounding melt growth medium (black line) until the crystal reaches a size of $1 \mathrm{~cm}$. The diffusive isotopic fractionation factor is $\Delta_{D}=-2.3 \%$ o $\left(\beta_{Z r}=0.054\right.$ in eq. 24$)$.

Movie S5: Same as Movie S4 except that the diffusive isotopic fractionation factor is $\Delta_{D}=-4.9 \%$ $\left(\beta_{Z r}=0.113\right.$ in eq. 24).

(iii) DTC model - Transient profiles during growth of a $\mathrm{Zr}$-poor crystal to $10 \mathrm{~cm}$ in size, at which point the profiles approach the steady-state.

Movie S6: Evolution of the $\mathrm{Zr}$ concentrations in a growing $\mathrm{Zr}$-poor crystal (blue line) and in the surrounding melt growth medium (black line) until the crystal reaches a size of $10 \mathrm{~cm}$.

Movie S7: Evolution of the Zr isotopic composition in a growing Zr-poor crystal (blue line) and in the surrounding melt growth medium (black line) until the crystal reaches a size of $10 \mathrm{~cm}$. The diffusive isotopic fractionation factor is $\Delta_{D}=-2.3 \%$ ( $\beta_{Z r}=0.054$ in eq. 24$)$.

Movie S8: Same as Movie S7 except that the diffusive isotopic fractionation factor is $\Delta_{D}=-4.9 \%$ $\left(\beta_{Z r}=0.113\right.$ in eq. 24$)$.

\section{(iv) DTC model}

Movie S9: Expected probability density distributions functions (PDFs) of the $\mathrm{Zr}$ isotopic compositions of $\mathrm{Zr}$ atoms in the evolving diffusive boundary layer. We only consider here locations where $C / C_{0}>3$. The diffusive $\mathrm{Zr}$ isotopic fractionation factor is $\Delta_{D}=-2.3 \%_{\mathrm{o}}\left(\beta_{Z r}=\right.$ 0.054 in eq. 24$)$.

Movie S10: Same as Movie S9 except that the diffusive isotopic fractionation factor is $\Delta_{D}=-4.9 \%$ $\left(\beta_{Z r}=0.113\right.$ in eq. 24$)$. 


\section{References}

(1) Smith, V. G.; Tiller, W. A.; Rutter, J. A Mathematical Analysis of Solute Redistribution during Solidification. Canadian Journal of Physics 1955, 33 (12), 723-745.

(2) Sio, C. K.; Roskosz, M.; Dauphas, N.; Bennett, N. R.; Mock, T.; Shahar, A. The Isotope Effect for Mg-Fe Interdiffusion in Olivine and Its Dependence on Crystal Orientation, Composition and Temperature. Geochimica et Cosmochimica Acta 2018, 239, 463-480.

(3) Syme, R. W. G.; Lockwood, D. J.; Kerr, H. J. Raman Spectrum of Synthetic Zircon (ZrSiO 4 ) and Thorite (ThSiO 4 ). Journal of Physics C: Solid State Physics 1977, 10 (8), 13351348. https://doi.org/10.1088/0022-3719/10/8/036.

(4) Gucsik, A.; Zhang, M.; Koeberl, C.; Salje, E. K. H.; Redfern, S. A. T.; Pruneda, J. M. Infrared and Raman Spectra of $\mathrm{ZrSiO} 4$ Experimentally Shocked at High Pressures. Mineralogical Magazine 2004, 68 (5), 801-811. https://doi.org/10.1180/0026461046850220.

(5) Quintard, P. E.; Barbéris, P.; Mirgorodsky, A. P.; Merle-Méjean, T. Comparative LatticeDynamical Study of the Raman Spectra of Monoclinic and Tetragonal Phases of Zirconia and Hafnia. Journal of the American Ceramic Society 2004, 85 (7), 1745-1749. https://doi.org/10.1111/j.1151-2916.2002.tb00346.x.

(6) Watson, E. B.; Harrison, T. M. Zircon Saturation Revisited: Temperature and Composition Effects in a Variety of Crustal Magma Types. Earth and Planetary Science Letters 1983, 64 (2), 295-304.

(7) Boehnke, P.; Watson, E. B.; Trail, D.; Harrison, T. M.; Schmitt, A. K. Zircon Saturation ReRevisited. Chemical Geology 2013, 351, 324-334.

(8) Millet, M.-A.; Dauphas, N.; Greber, N. D.; Burton, K. W.; Dale, C. W.; Debret, B.; Macpherson, C. G.; Nowell, G. M.; Williams, H. M. Titanium Stable Isotope Investigation of Magmatic Processes on the Earth and Moon. Earth and planetary science letters 2016, 449, 197-205.

(9) Helz, R. T.; Kirschenbaum, H.; Marinenko, J.; Qian, R. Whole-Rock Analyses of Core Samples from the 1967, 1975, 1979 and 1981 Drillings of Kilauea Iki Lava Lake, Hawaii; 2331-1258; US Geological Survey, 1994.

(10) Finch, R. J.; Hanchar, J. M.; Hoskin, P. W.; Burns, P. C. Rare-Earth Elements in Synthetic Zircon: Part 2. A Single-Crystal X-Ray Study of Xenotime Substitution. American Mineralogist 2001, 86 (5-6), 681-689.

(11) Howard, C.; Hill, R.; Reichert, B. Structures of ZrO2 Polymorphs at Room Temperature by High-Resolution Neutron Powder Diffraction. Acta Crystallographica Section B: Structural Science 1988, 44 (2), 116-120.

(12) Merlino, S.; Pasero, M.; Bellezza, M.; Pushcharovsky, D. Y.; Gobetchia, E. R.; Zubkova, N. V.; Pekov, I. V. The Crystal Structure of Calcium Catapleiite. Canadian Mineralogist 2004, 42 (4), 1037-1045. https://doi.org/10.2113/gscanmin.42.4.1037. 